\title{
On the Paradox of Criminal Investigation from the Perspective
}

\section{of One-Dimensional Time}

\author{
Yutong $\mathrm{Zou}^{1 *}$ \\ ${ }^{1}$ School of Law, Sichuan University, Chengdu, China \\ *Yutong Zou, E-mail: 610372060@qq.com
}

Received: July 28, 2017

Accepted: August 8, 2017

Online Published: August 21, 2017

doi:10.22158/wjssr.v4n3p265

URL: http://dx.doi.org/10.22158/wjssr.v4n3p265

\begin{abstract}
This paper conducts a primary explanation of the concept of paradox of criminal investigation. Besides, it proposes that the very existence of paradox of criminal investigation is due to its one-dimensional time, which meanwhile leads to the indigestibility of the paradox. Therefore, the digestion of paradox of criminal investigation should be abandoned, so as to control the cost brought by it as much as possible.
\end{abstract}

\section{Keywords}

paradox of criminal investigation, one-dimensional time, human rights

\section{Paradox and Paradox Digestion}

N. Re held that "para-" means "beyond", and "-doxa" means "belief". With the development of history, more meanings have been attached to the word of paradox, with its denotation constantly being expanded. Relevant scholars have divided the concept of paradox into rigid paradox and generalized paradox. For rigid paradox, first of all it should be the paradox of logical meaning. Whether it be a logical paradox in narrow or wide sense, it must possess "three elements" of logical paradox as long as it is a paradox in rigid sense. For generalized paradox, it may be the paradox of rhetorical meaning, or the paradoxical situation or action in the level of practice, or even a common logical contradiction. The paradox of criminal investigation mentioned in this paper is a generalized paradox.

And there is one specific concept corresponding to paradox, i.e., paradox digestion. Firstly, it remains disputed whether paradox can be digested, but based on whether or not paradox still exist before and after digestion, it can be classified into different types. This paper will not belabor here. And famous paradox digestion schemes include Russell's theories of type and Quine's NF system. In semantic sense, the paradox digestion in this paper is semantically closer to paradox resolution or the resolution of contradictions as mentioned before. 


\section{Explanation of Paradox of Criminal Investigation and Its Digestion in Current Academia}

There are few discussions on paradox of criminal investigation in current academia. At present, among discussions of paradox of criminal investigation, most of them divide it into three types, namely procedural justice and substantive justice of criminal investigation, criminal investigation and human rights guarantee, enforceability and arbitrariness of criminal investigation.

For procedural justice and substantive justice of criminal investigation, it can be deemed as the embodiment of the disputes between substantive justice and procedural justice in the area of criminal investigation, namely whether to follow the so-called "visible" procedural justice or substantive justice. For the paradox in this aspect, relevant scholars hold that the establishment of illegal evidence elimination system and the standardization of evidence obtaining means have fundamentally wiped out the evidences violating procedural justice, hence ensuring the predominant position of procedural justice. Therefore, this paradox is already digested. For the paradox of enforceability and arbitrariness of criminal investigation, most scholars have a relatively unified viewpoint that paradoxes are mainly from semantic classification in the academia. On the one hand, this paradox can be digested through semantic reconstruction, but on the other hand, it shares an exterior-interior relationship with the previous procedural justice and substantive justice of criminal investigation, and criminal investigation and human rights guarantee. For example, enforceable investigations and arbitrary investigations in essence are separated according to the degree of violation against human rights.

Meanwhile, the paradox of criminal investigation and human rights guarantee refers to that human rights cannot be violated in the process of criminal investigation. For example, after a crime is committed and the criminal investigation procedure initiated, basic criminal investigation actions like arresting suspects and summoning of relevant witnesses must be based on the sacrifice of right of freedom of the people involved. There are many disputes to this type of issues. Some scholars hold that this paradox can be deemed digested as it conforms to the principle of criminal investigation that the violated rights are less than those protected. While some others think that just like the dilemma for switchman, rights can only be used as purpose instead of means just like people, because no comparative choice can be made among rights.

\section{Core of Paradox of Criminal Investigation and Its Indigestibility from the Perspective of} One-Dimensional Time

Following the above discussions, it has been understood that enforceability and arbitrariness of investigation shares an exterior-interior relationship with procedural justice and substantive justice of investigation as well as investigation and human rights guarantee. Meanwhile, semantic discussions of investigation and human rights guarantee normally avoids comparing the balance between rights, because rights cannot be compared, and investigations violating human rights will not be deemed as right violation but judicial cost. 
Furthermore, let's compare the procedural justice and substantive justice of investigation actions. As mentioned above, this is the embodiment of disputes between substantive justice and procedural justice, so the paradox of investigation in this aspect only possesses the commonality of procedural justice and substantive justice without any individual features. On the one hand, the disputes between procedural justice and substantive justice are more about human rights guarantee, because procedural justice not only aims for realizing human rights guarantee but also enjoys attributes of human rights. The fundamental dispute between them lies in the excessively high cost of substantive justice in pursuing procedural justice. Regulating the conflicts therein means seeking balance between error loss and information cost 2. Seen from this view, it happens to be consistent with the cost concept of semantic digestion in investigation and human rights guarantee.

Through the above logical reasoning, it is not difficult to conclude that it is not necessary for the academia to divide paradox of criminal investigation into the three types, namely procedural justice and substantive justice, criminal investigation and human rights guarantee, enforceability and arbitrariness of criminal investigation. The three of them point to the same paradox, namely unavoidable cost for realizing the goal of criminal investigation or social evils for realizing the goal of criminal investigation in cracking crimes.

The fundamental reason leading to this paradox lies in the one-dimensional time of the physical world we are in, that is, the time cannot be recovered once lost. Once the crime happens, it will be permanently fixed so that we cannot go back to stop it because of one-dimensional time, and its consequences will further influence the following time and space with passage of time. Meanwhile, because of one-dimensional time, we can only look at the crime in a recalling angle. All current criminal investigations, including crime scene investigation, evidence solidification and investigation tests, aim for restoring the crime scene. And it also determines that our criminal investigation actions will never restore $100 \%$, i.e., any crime, no matter how simple it is, cannot be thoroughly investigated regardless of the technologies. Take the Ebbinghaus Forgetting Curve for an example. The memory capacitance remains $58.2 \%$ after $20 \mathrm{~min}, 44.2 \%$ after $1 \mathrm{~h}, 35.8 \%$ after $8-9 \mathrm{~h}, 33.7 \%$ after $1 \mathrm{~d}, 27.8 \%$ after 2d, and $25.4 \%$ after $6 \mathrm{~d}$. Evidences like witness testimonies, confessions of criminal suspect and statement of victim are all restrained by the memory curve of human brain, i.e., all testimonies cannot be fully trusted.

Exactly because of the one-dimensionality of time, in criminal investigation actions there exists a paradox of making a thorough investigation of corpus delicti to maintain social order and meanwhile paying corresponding price or cost. The cost mainly includes the following two types. some crimes cannot be uncovered because of the traceability and restorability of criminal investigation, and false cases can also arise because of failing to completely and accurately obtain the corpus delicti. Secondly, under current technologies, in order to conduct a thorough investigation into the facts as much as possible, there will be inevitably criminal investigations violating human rights. 
Another approach is proposing quasi-crime control based on one-dimensionality of time, a concept of criminal investigations before crime. Let's not bother whether the concept has run counter against the concept of criminal investigation itself. The concept of criminal investigation refers to the activities of organs like procuratorates and public security authorities in criminal proceedings that conduct professional investigation work and adopt relevant enforceable measures to ascertain criminal facts and capturing criminal suspects. There is no the statement of criminal investigation before crime from the legislation to the decision of whether to hand the case over for prosecution. Even though this action falls into criminal investigation, the means adopted like large-scale installation of cameras and elimination investigation will seriously harm social order. For large-scale investigation of people, if the investigation of people takes place on a vital transport line, setting up roadblocks will no doubt influence the transportation and daily life of citizens; and if it takes place in entertainment venues or private hotels, normal operation of industrial and commercial units will also be seriously affected. Conducting investigation on virtual network will no doubt damage the internet access right and freedom of speech of people, and throw citizens into the feeling of being reduced into a police state, where the big brother is watching over them all the time.

Based on the above analyses, the reason why the paradox of criminal investigation can come into being lies in one-dimensionality of time, while its digestion depends on the cracking of the one-dimensionality of time. Then can it be cracked?

Under the current time-space environment, what we perceive is still the macroscopic and low-speed world where quantum mechanics cannot function, and what rules the world is the physical law of relativity. Compared with the classical physics built by Newton, relativity overturned its absolute view of time and space. However, even in the relative time-space view constructed by restricted relativity, the passing speed of time will only shorten but never backflow when the moving speed of object approaches light speed. There in the one-dimensionality of time cannot be changed, so the paradox of criminal investigation under current time and space can not be digested.

\section{Conclusion}

After the conclusion that the paradox of criminal investigation cannot be digested is obtained through analyses from the perspective of one-dimensional time, it should be realized that we need to look squarely at the unavoidable violation of relevant rights in criminal investigations, and what we can do is to spare no efforts to narrow down the violation cost while ensuring the effectiveness of criminal investigation actions.

\section{References}

Andre, F. (2002). Russell's way out of the paradox of propositions. History and Philosophy of Logic, 23(3). https://doi.org/10.1080/01445340210161017 
Bert-Jaap, K. (2003). The Shifting "Balance" Between Criminal Investigation and Privacy. Information, Communication \& Society, 6(3).

Li, C. T. (2012). Crime Prevention Technologies and Applications for Advancing Criminal Investigation.

Re-scher, N. (2001). Paradoxes: Their Roots, Range, and Resolution. Carus Publishing Company.

Sang, B. (2011). Economic Restatement on Jurisprudential Topics. Studies in Laws and Business, 2011(2).

Yang, Y. (2010). Fundamental Mathematical Equations of Relativity. Journal of Beijing Information Science \& Technology University, 2010(6). 